\title{
Endovascular options in the treatment of delayed ischemic neurological deficits due to cerebral vasospasm
}

\author{
A review \\ Christopher S. Eddeman, M.D., Ph.D., ${ }^{1,2}$ Michael C. Hurley, M.D.,, 2 \\ Andrew M. Naidech, M.D., M.S.P.H., ${ }^{1,3}$ H. Hunt BatJer, M.D., 1 \\ AND BERnARD R. BENDOK, M.D. 1,2 \\ Departments of ${ }^{1}$ Neurological Surgery, ${ }^{2}$ Radiology, and ${ }^{3}$ Neurology, Feinberg School of Medicine, Chicago, \\ Illinois
}

The second leading cause of death and disability in patients with aneurysmal subarachnoid hemorrhage (SAH) is delayed cerebral ischemia due to vasospasm. Although up to $70 \%$ of patients have been shown to have angiographic evidence of vasospasm, only 20-30\% will present with clinical changes, including mental status changes and neurological deficits that necessitate acute management. Endovascular capabilities have progressed to become viable options in the treatment of cerebral vasospasm. The rationale for intraarterial therapy includes the fact that morbidity and mortality rates have not changed in recent years despite optimized noninvasive medical care. In this report, the authors discuss the most common endovascular options - namely intraarterial vasodilators and transluminal balloon angioplasty - from the standpoint of mechanism, efficacy, limitations, and complications as well as the treatment algorithms for cerebral vasospasm used at our institution. (DOI: 10.3171.2008.11.FOCUSO8278)

$\begin{array}{llll}\text { KEY WORDS } & \text { calcium antagonist } \quad \text { delayed ischemic neurological deficit } \\ \text { endovascular procedure } & \bullet \quad \text { intraarterial vasodilator } & \bullet \\ \text { subarachnoid hemorrhage } & \bullet \quad \text { transluminal balloon angioplasty } & \bullet & \text { vasospasm }\end{array}$

$\mathrm{D}$ ESPITE the fact that the initial mortality rate from aneurysmal SAH is very high $(30-70 \%)$, the secondary effects also pose a significant risk of morbidity and mortality, namely delayed cerebral ischemia due to vasospasm, the second leading cause of death and disability in patients with aneurysmal SAH ${ }^{29,35,47}$ Often occurring in the larger proximal arteries either involved in the circle of Willis or branching from it, this delayed, reversible narrowing of the cerebral vessels is thought to occur 3-14 days after the hemorrhagic event. ${ }^{17,29}$ Despite years of investigation, the exact pathophysiology of cerebral vasospasm still remains largely unknown..$^{29}$ Therefore, the ability to predict which patients are likely to suffer the deleterious effects of vasospasm is difficult at best. Factors such as Hunt and Hess grade as well as the initial presence, volume, density, and duration of the blood clot

Abbreviations used in this paper: $\mathrm{ICA}=$ internal carotid artery; $\mathrm{ICP}=$ intracranial pressure; TBA $=$ transluminal balloon angioplasty; $\mathrm{TCD}=$ transcranial Doppler; triple- $\mathrm{H}=$ hypervolemia, hypertension, and hemodilution. determined by CT scanning have been shown to be predictors for the occurrence of vasospasm, although more certainly exist. $12,14,17,29,34,44$ The cerebral vasospasm literature suggests that the mortality rate is approximately $7 \%$ with another $7 \%$ of individuals suffering devastating neurological deficits. ${ }^{12,14,17,29,34,44}$ Although up to $70 \%$ of patients have been shown to have angiographic evidence of vasospasm, only $20-30 \%$ will actually present with clinical changes, including mental status changes and neurological deficits, necessitating acute management. $12,14,17,29,34,44$

\section{Endovascular Options in Cerebral Vasospasm}

The current gold standard of assessing the extent of cerebral vasospasm once clinical changes have presented is catheter-based cerebral angiography. However, cerebral angiography is not a feasible method of prophylactic monitoring due to the procedural risk of exposure to the patient. Other techniques of prophylactic cerebral vasospasm monitoring - for instance, TCD ultrasonography, CT angiography, or cerebral CT perfusion scanning- 
TABLE 1: Intraarterial calcium antagonists and their relative cardiovascular effects*

\begin{tabular}{lcccc}
\hline & \multicolumn{4}{c}{ Relative Effects† } \\
\cline { 2 - 5 } \multicolumn{1}{c}{ Agent } & Vasodilation & $\begin{array}{c}\text { Myocardial } \\
\text { Depression }\end{array}$ & $\begin{array}{c}\text { SA Node } \\
\text { Suppression }\end{array}$ & $\begin{array}{c}\text { AV Node } \\
\text { Suppression }\end{array}$ \\
\hline nicardipine & 5 & 0 & 1 & 0 \\
diltiazem & 3 & 2 & 5 & 4 \\
verapamil & 4 & 4 & 5 & 5 \\
\hline
\end{tabular}

* Modified from data in Mindea et al. Abbreviations: AV = atrioventricular; $\mathrm{SA}=$ sinoatrial.

† Relative effects are ranked from 0 (no effect) to 5 (most prominent).

are currently used. $1,7,16,18,25,28,40,45$ Transcranial Doppler ultrasonography is probably the most common noninvasive method but provides little quantitative information, thereby limiting one's ability to use it for grading severity of the lesion; it can produce false-positive results when patients are given medications that increase blood pressure. The use of CT angiography and CT perfusion scanning has increased use over recent years due to their more widespread availability as well as literature support. However, when used alone, CT angiography may be specific for severe large-vessel vasospasm, but it has low sensitivity for mild and moderate vasospasm as well as being of limited use in vessels that are either near bone or intracranial hardware (for example, aneurysm clips and intracranial stents). Most institutions use some combination of the aforementioned modalities to assess cerebral vasospasm that may or may not warrant therapy.

The management goal in cases of cerebral vasospasm is to optimize cerebral perfusion without causing cerebral or systemic injury to the patient. Measures to address spasm are usually initiated after the patient is admitted to the hospital. These measures include administration of nimodipine and placing a central venous catheter. ${ }^{17,24,44,48}$ Some institutions, in an effort to reduce the blood clot burden on the cerebral vessels, will insert a lumbar drain for CSF drainage, which has been reported to have some effect on the incidence of cerebral vasospasm. ${ }^{22}$ Once the aneurysm is secured, more aggressive forms of medical management are typically instituted after a spasm is diagnosed, such as triple-H therapy, or hyperdynamic therapy without intentional anemia. ${ }^{26,32}$ Triple-H therapy improves cerebral perfusion and can improve clinical outcomes, ${ }^{17,24,44,48}$ but it has not been definitively shown to prevent cerebral vasospasm. ${ }^{24,29}$ The prophylactic use of triple-H therapy is typically not indicated. ${ }^{33}$ While triple-H therapy has been shown to be effective during the onset of vasospasm, it does not always prevent cerebral ischemia or infarction from vasospasm..$^{33}$ Moreover, some patients have significant medical comorbidities including vascular and cardiac disease and subsequently may not medically tolerate triple-H therapy. Despite optimal medical management, including, triple-H therapy, Awad et al. ${ }^{2}$ have reported that $33.3 \%$ of patients treated with triple- $\mathrm{H}$ therapy had a minor neurological deficit, and $19 \%$ had a major neurological deficit or were dead due to vasospasm.

Endovascular capabilities have progressed to be- come viable options in the treatment of cerebral vasospasm. The rationale for intraarterial therapy includes the fact that morbidity and mortality have not changed in recent years despite optimized noninvasive medical care. Furthermore, the aggressive endovascular treatment of cerebral vasospasm appears to improve neurological outcomes without putting the patient at significant risk of complications that can accompany prolonged triple$\mathrm{H}$ therapy. Eskridge et al..$^{10}$ have suggested the following criteria to determine the need for endovascular therapy for cerebral vasospasm: 1) new neurological deficit not explained by other causes; 2) no CT evidence of cerebral infarction; 3) failure of maximal medical therapy (triple$\mathrm{H}$ therapy); and 4) angiographic evidence of vasospasm in the same distribution as the neurological deficit.

The most common endovascular therapies for cerebral vasospasm include intraarterial vasodilator infusion, transluminal balloon angioplasty, or a combination of these treatments. ${ }^{15,17,18,21,24,31,37,38,48}$ Although intracranial stents have been used to maintain patency in severely spastic arteries, their use has not been widespread, and therefore, any discussion is beyond the scope of this article. ${ }^{23,47}$ Our goal is to discuss the most common endovascular options from the standpoint of mechanism, efficacy, limitations, and complications. Finally, we discuss the treatment algorithms for cerebral vasospasm used at our institution.

\section{Intraarterial Vasodilators}

Given the fact that most institutions initiate some form of systemic preventive calcium antagonist therapy in SAH patients before and after definitive aneurysm therapy, intraarterial application of calcium antagonists seems like an intuitive application especially in light of the inability of endovascular balloons to safely reach distal intracranial vessels. The most studied intraarterial pharmacological agent to date is papaverine, an opium alkaloid thought to alter adenosine $3^{\prime}, 5^{\prime}$-cyclic monophosphate levels in smooth muscles., ${ }^{915,21,27,31}$ The half-life is approximately 2 hours. In their 2005 review of intraarterial agents for treatment of cerebral vasospasm, Hoh

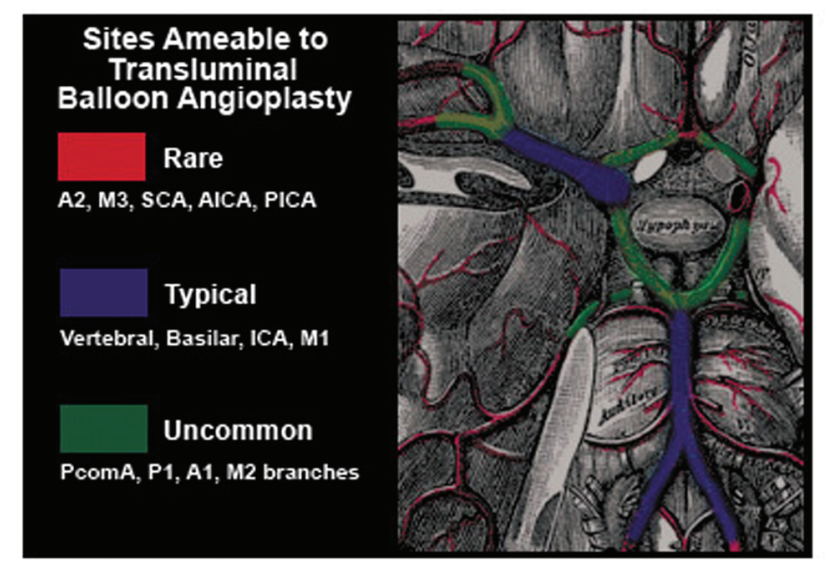

Fig. 1. Artist's drawing of sites amenable to TBA. AICA = anterior inferior cerebellar artery; PcomA = posterior communicating artery; PICA = posterior inferior cerebellar artery; SCA = superior cerebellar artery. 


\section{Endovascular options for delayed ischemic neurological deficits}

and Ogilvy ${ }^{15}$ reported that although papaverine produced clinical improvement in $43 \%$ of treated patients, this was only a transient effect and thus required multiple treatments that lead to a variable but increased complication profile. In addition, Smith et al. ${ }^{41}$ reported several cases of gray matter injury linked to direct neurotoxicity thought directly due to papaverine intraarterial infusion. Therefore, papaverine's use as an intraarterial vasodilator has since decreased.

Several other intraarterial calcium antagonists have been used in the treatment of cerebral vasospasm in an off-label use, because the FDA has not approved the use of these agents (that is, verapamil, ${ }^{11,19}$ nimodipine, ${ }^{5,6}$ and nicardipine $^{3,42}$ ) for this purpose (Table 1). Verapamil is a phenylalkylamine calcium channel blocker that inhibits voltage-gated calcium channels in the arterial wall smooth muscle cells and results in vasodilation. The half-life is approximately 7 hours. Verapamil was used by Feng et al. ${ }^{11}$ in 29 patients who underwent 34 procedures; $52 \%$ were treated with verapamil alone, and this resulted in $44 \%$ experiencing increased vessel diameters and $33 \%$ exhibiting neurological improvement without complication or ICP issues. Nimodipine is a dihydropyridine agent thought to work similarly to verapamil with a slightly longer half-life of 9 hours. Biondi et al. ${ }^{6}$ treated 25 patients in 30 procedures and used 1-5 mg of nimodipine per session. They reported a $76 \%$ rate of clinical improvement in the first 24 hours with $43 \%$ demonstrating vessel dilation. There were no reported complications or changes in ICP. Nicardipine is another dihydropyridine agent with a half-life $\sim 16$ hours. Badjatia et al. ${ }^{3}$ reported on 18 patients with 44 vessels treated with nicardipine alone. Neurological improvement was demonstrated in $42 \%$ without significant systemic effects. However, ICP was transiently elevated in 4 patients and persistently elevated in 1 . Tejada et al. ${ }^{42}$ demonstrated clinical improvement in $91 \%$ of their population (10 of 11 patients) and a $60 \%$ improvement in vessel diameter compared with pretreatment status after using higher doses of intraarterial nicardipine. Other noncalcium channel antagonists, such as magnesium sulfate, 3-hydroxy-3-methylglutaryl-CoA reductase inhibitors, nitric oxide donors, and endothelin-1 antagonists have been used, but their application has not been widespread.

Methodologies regarding the application of various intraarterial vasodilators typically involve slow infusion via the proximal guide catheter into the ICA, in cases of mild to moderate vasospasm, or superselective infusion, in cases of severe proximal vasospasm. There are no known reports in the literature that specifically document the effectiveness of either technique, which is usually undertaken at the discretion of the treating physician.

Despite the apparent success of intraarterial pharmacological agents in improving both the angiographic appearance and clinical sequelae of cerebral vasospasm, poorly responsive severe vascular attenuation causing flow limitation warrants urgent angioplasty, if accessible, to avoid incipient infarction. Also, it is common to see a relapse in clinical vasospasm 12-24 hours after an initial response to an intraarterial pharmaceutical agent. ${ }^{15,23}$

\section{Transluminal Balloon Angioplasty}

Mechanical dilation of intracranial vessels has been performed in humans since Zubkov et al. ${ }^{46}$ reported their results, obtained in selected patients with large-vessel spasm. Although the specific mechanism of action responsible for the effects of TBA are not well understood, several are likely to be at play, including but probably not limited to disruption or dysfunction of smooth muscle cells, extracellular matrix, or connections between the basement membranes of the cells..$^{30,39,48}$ Although it has been shown that TBA causes smooth muscle and endothelial cell flattening, some extracellular matrix disruption, and denudation of the endothelial lining, TBA is not thought to cause major irreversible structural damage. ${ }^{29,30}$ These mechanisms usually result in a robust patency after angioplasty, with resilience to further spasm, but it should be noted that these vessels may also become less responsive to pharmacological vasodilators. ${ }^{29,30}$

The segments of the intracranial circulation accessible to TBA are generally restricted to the larger $(>2 \mathrm{~mm})$ proximal vessels of the circle of Willis and less commonly their immediate more distal branches (Fig. 1). Typical locations of TBA are the vertebral artery, basilar artery, supraclinoidal ICA, and $\mathrm{M}_{1}$ segment. Less common locations, due to their often smaller diameter and higher risk of vessel rupture are the posterior communicating, ${ }^{20} \mathrm{~A}_{1}$, $\mathrm{M}_{2}$, and $\mathrm{P}_{1}$ arteries. Segments that are usually avoided altogether due to the limits of the balloons available are the PICA, AICA, $\mathrm{P}_{2}, \mathrm{~A}_{2}$, and $\mathrm{M}_{3}$ arterial branches.

Two differing balloon technologies have been used for treatment of vasospasm: coronary balloons and the more compliant intracranial balloons.

Transluminal balloon angioplasty catheters have undergone their greatest refinement in the far larger field of coronary intervention, and many of these have been successfully adopted for intracranial use. They comprise a relatively stiff balloon membrane composed of polyethylene or nylon and a double-lumen shaft-one for balloon inflation and the other for passage of a range of 0.014-in guidewires. Shorter coronary balloons, such as the 9-mmlong Maverick (Boston Scientific), allow greater maneuverability and cause less vessel straightening on inflation. Given the robust nature of these balloons, they should be sized conservatively because an oversized balloon can easily cause vessel rupture with catastrophic consequences. A 2-mm-diameter balloon will usually suffice for middle cerebral artery angioplasty and, in the rare case in which an $\mathrm{M}_{2}$ or $\mathrm{A}_{1}$ lesion is treated, a 1.5-mm-diameter balloon should suffice. These catheters have a tightly calibrated size to inflation pressure. Similar technology has been developed for dedicated intracranial use, with the Gateway balloon (Boston Scientific) available with 1.5to 4-mm-diameter and 10-, 15-, and 20-mm-length balloons, designed primarily for the treatment of intracranial atherosclerotic stenosis.

A second balloon technology relies on a softer semipermeable silicone/elastomer membrane loaded on a single-lumen, more flexible, catheter shaft. Examples of this technology include the Hyperglide $(4 \times 10 / 15 / 20 / 30$ $\mathrm{mm})$ and the Hyperform $(4 / 7 \times 7-\mathrm{mm})$ balloon catheters (EV3). These balloons are designed to navigate over a 


\section{S. Eddleman et al.}

0.010-in X-Pedion guidewire. The Hyperform is more compliant, but the more elongated Hyperglide balloon shape is better suited to angioplasty of long segments of spastic arteries. The catheter lumen distal to the balloon tapers and is effectively occluded by the guidewire, causing injected liquid to divert into and expand the balloon. To avoid blood tracking back into the catheter lumen and balloon, the guidewire must not be allowed to retract into the catheter when intravascularly placed; this can result in less balloon opacification, unsuspected overinflation, or difficulty in deflation. The balloon is usually inflated with a highly calibrated threaded 1-ml Cadence (EV3) syringe that enables adjustments in the $0.01-\mathrm{ml}$ range (the $4 \times 7-\mathrm{mm}$ Hyperform is fully inflated at $0.06 \mathrm{ml}$ ). The inflated diameter of these balloons is calibrated to the volume injected rather than to an insufflation pressure. As they tend to have a relatively large maximum inflation diameter, these balloons need to be keenly observed and inflation must cease once the soft balloon starts to conform to the vessel lumen. Several operators use a 0.08-in wire such as the Mirage (Balt), claiming that this confers a safety mechanism by allowing the balloon to decompress when overinflated. All of the aforementioned balloons should be inflated with a $>50 / 50$ mixture of 300 $\mathrm{mg} / \mathrm{ml}$ iodinated contrast with saline to enable safe visualization. Higher concentrations of contrast may cause poor balloon deflation.

The angiographic and clinical improvements after TBA are variable and have been reported in several studies. $4,15,18,24,39,43,47$ In their 2005 review of the literature regarding endovascular therapy for cerebral vasospasm, Hoh and Ogilvy ${ }^{15}$ reported an overall clinical improvement in $62 \%$ of patients treated with TBA. Despite the favorable results, these studies were not compared with matched controls. Recently, Jestaedt et al. ${ }^{18}$ have shown that TBA-treated vascular territories had a lower rate (7\%) of infarction compared with territories not treated with TBA (38\%). To establish whether the timing of TBA led to different outcomes, Rosenwasser et al. ${ }^{36}$ reported that $90 \%$ of patients treated with TBA within a 2-hour window exhibited angiographic improvement, with $70 \%$ clinically improved, whereas patients treated outside the 2-hour window exhibited similar angiographic improvement $(88 \%)$ but with only $40 \%$ sustaining clinical improvement. Even with the reported success rate of TBA for cerebral vasospasm, many patients still suffer from significant morbidity due to vasospasm, calling into question the idea of prophylactic TBA. Very recently, the results of a Phase II study, ${ }^{47}$ which examined prophylactic TBA in patients with Fisher Grade III SAH, were published and did not demonstrate a significant difference in the primary endpoint (Glasgow Outcome Scale score) but did demonstrate a trend toward fewer patients developing vasospasm or needing therapeutic TBA.

Although an effective treatment, TBA's attendant complications can be devastating. ${ }^{10,18,23,36,39,43,48}$ The most feared complication is vessel rupture, which can occur when there is discordant balloon diameter to vessel size. Occasionally, in the absence of a prespasm baseline angiographic study, the "normal" size of a spastic vessel must be estimated based on anatomical assumptions.
Special care must be taken to avoid overdilating a congenitally hypoplastic artery such as is commonly found in the $\mathrm{A}_{1}, \mathrm{P}_{1}$, and posterior communicating artery segments. In cases of critical spasm, there may be minimal distal vascular opacification with an attendant risk of catheter malpositioning-for example, having the balloon tip projecting into a proximal lenticulostriate perforator rather than an $\mathrm{M}_{2}$ segment will likely result in rupture on inflation. Arterial dissection may occur without frank perforation and can result in flow limitation, thrombosis, or pseudoaneurysm formation. Shearing forces due to traction on an inflated balloon must be avoided by ensuring complete balloon deflation before catheter manipulation. Thrombus can also occur around the balloon or within the catheter lumen, particularly in patients recovering from SAH in whom there is a thrombogenic tendency, and patients should undergo heparinization to an activated clotting time of at least 250 seconds throughout the procedure unless contraindicated. Finally, the reestablishment of cerebral blood flow into an area that has suffered prolonged ischemia may result in reperfusion injury or even lead to hemorrhage, sometimes necessitating evacuation of the resultant hematoma.

\section{Combination Therapy}

In cases of severe vasospasm, because a flow-limiting stenosis is likely to be present, the ability of intraarterial agents to reach distal locations is unlikely. As a result, TBA appears to be a useful first option. Once the proximal vessel is dilated with TBA, the accessibility of distal vessels to an infusion of intraarterial pharmacological agents improves. However, the initial intraarterial vasodilator infusion may increase the proximal diameter of a target vessel such that a balloon catheter can be more safely placed and subsequently dilated. Controversy remains as to whether intraarterial vasodilation should be performed before TBA. Megyesi et al. ${ }^{30}$ have demonstrated that after vessels had undergone TBA, their responsiveness to vasodilators was less pronounced. Furthermore, several authors have shown that while intraarterial vasodilation can be accomplished without TBA, intraarterial monotherapy typically leads to more retreatments. ${ }^{8,15,48}$ It is the senior author's (B.R.B.'s) belief that TBA performed up front followed by intraarterial infusion of vasodilators leads to a more durable proximal therapy and also treats distal vasospasm via intraarterial vasodilator infusion. Although several studies have examined the combination of intraarterial agents and TBA, efficacy data are limited. Firlik et al. ${ }^{13}$ used papaverine in addition to TBA in 8 of 14 patients and only found $50 \%$ of the vessels to have had an angiographic effect, therefore concluding that the combination only had a marginal effect. Furthermore, newer generation intraarterial agents, such as nicardipine, have not been reported in combinational studies with TBA. These studies are ongoing at our institution.

\section{Northwestern Algorithm for Vasospasm Therapy}

In an effort to improve the management of cerebral vasospasm, we have developed an algorithm to guide therapy (Fig. 2). The most important factor for detecting 


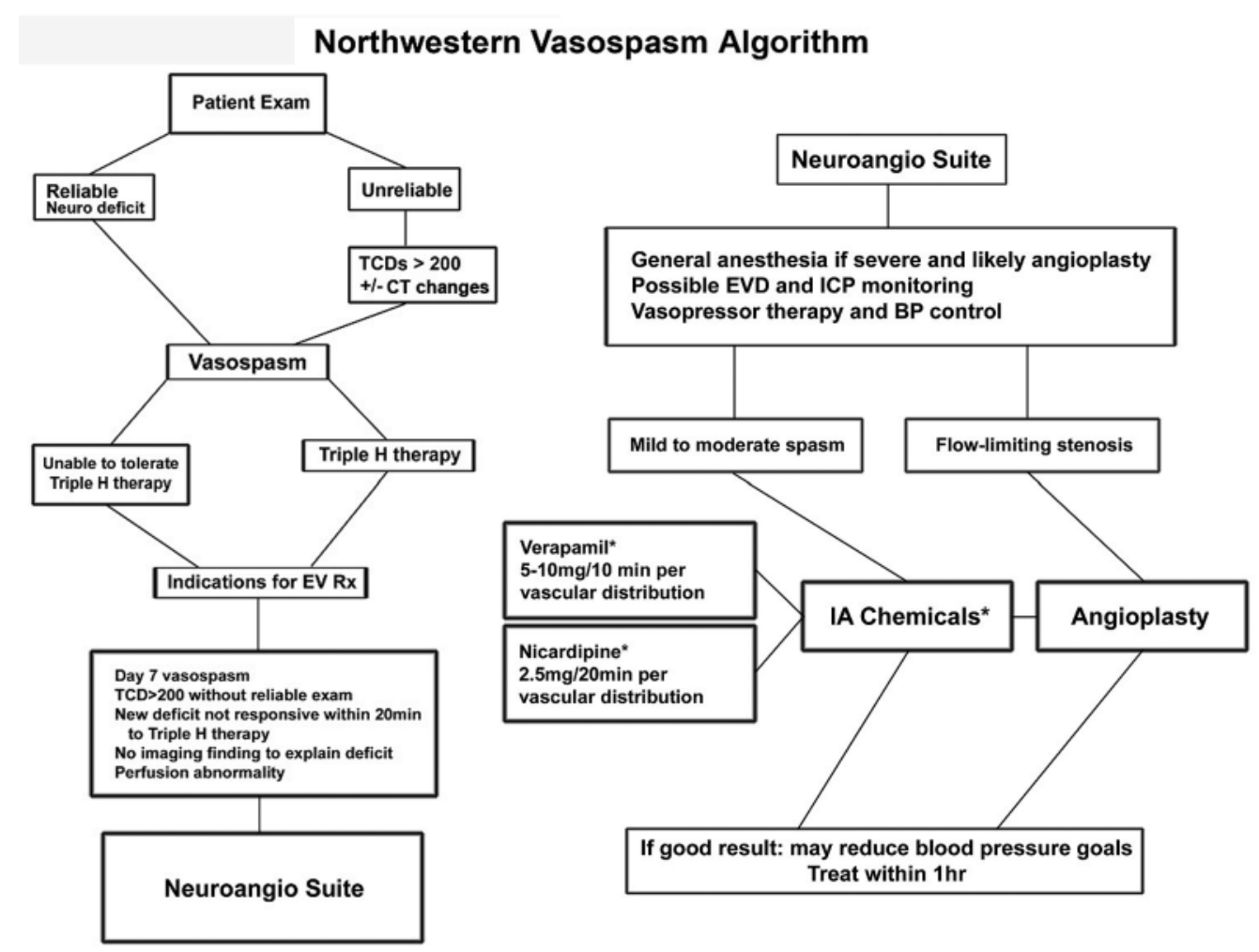

Fig. 2. Algorithm showing the management steps in treating cerebral vasospasm. $B P=$ blood pressure; $E V D=$ extraventricular drain; EVRx = Endovascular therapy; IA = intraarterial.

the development of cerebral vasospasm is the patient's examination. The neurological examination can either be reliable - that is, reproducible in an awake and alert patient-or unreliable-that is, in either a comatose or significantly confused patient. If there is a drop in the Glasgow Coma Scale score by at least 1 point or in the National Institutes of Health Stroke Scale by at least 2 points in a reliable patient or changes in either TCD ultrasonography measurements or perfusion imaging in an unreliable patient, that patient is assumed to have some element of vasospasm unless proven otherwise. Our initial management option is to optimize medical therapy, primarily through hyperdynamic therapy. ${ }^{26,32}$ The patient's neurological examination or assessment parameters are closely followed. If the patient improves and can tolerate medical therapy, it is continued. However, there are a group of patients that either does not respond to medical therapy (no improvement in neurological examination or TCD/perfusion parameters) or cannot tolerate medical therapy due to cardiac or renal comorbidities. These patients are candidates for endovascular intervention. Other potential indications for endovascular evaluation and/or intervention include findings on short-term followup angiography after aneurysm occlusion (usually Days 5-9), TCD ultrasonography measurements $>200$ without a reliable examination, any new neurological deficit not responsive within 20-30 minutes of its institution with a reliable examination, absence of imaging findings to explain the deficit, and any new perfusion deficit in a territory that can explain the deficit. At this point, the patient is taken to the neuroangiography suite for a diagnostic cerebral angiogram. General anesthesia is typically induced if severe vasospasm is suspected or if TBA is likely. Depending on the status of the patient, an external ventricular drain or other ICP monitoring may be indicated. Furthermore, vigilant blood pressure monitoring is maintained to avoid any unanticipated reductions in blood pressure from the use of intraarterial vasodilators. For mild to moderate vasospasm, intraarterial vasodilators are initially used (verapamil or nicardipine). While the senior author has not observed a significant difference between these 2 intraarterial agents, the agent may be selected with regard to the side-effect profile (Table 1) as it relates to the patient. However, if one notes a flowlimiting stenosis in a proximal vessel, TBA can be used initially and potentially followed by intraarterial vasodilator infusion. The balloon is inflated distally first and then proximally, and it usually covers the length of the spastic segment. The guidewire is typically left in place during balloon inflation, which has been shown to result in lower vessel rupture risk $^{43}$ and in case distal access is necessary for replacement or repositioning of the balloon. Transluminal balloon angioplasty of cerebral vessels is done to approximately $50-90 \%$ of the original size. Overdilation is avoided to reduce the risk of rupture. If there is satisfactory and sustained angiographic improvement, the patient is taken back to the neurointensive care unit and immediately assessed. If the patient has clinically improved or cerebral perfusion has improved, as evidenced on angiography without significant residual spasm, then 
TABLE 2: Comparison of coronary versus neurological balloons

\begin{tabular}{lcc}
\hline \multicolumn{1}{c}{ Feature } & Coronary & Neurological \\
\hline $\begin{array}{l}\text { wire removal \& infusion } \\
\text { ability }\end{array}$ & yes & no \\
precision & yes & no \\
trackability & no & yes \\
very small vessels & yes & no \\
length of balloon & no & yes \\
minimal number of inflations & no & yes \\
lower risk of vessel rupture & maybe & no \\
balloon compliance & no & yes \\
flexibility in wire choice & yes & no \\
\hline
\end{tabular}

*For small vessels.

consideration can be given to gradually reducing the blood pressure target. No data currently exist to guide this approach. Endovascular therapy often needs to be repeated on subsequent days based on parameters outlined for initial therapy above.

\section{Conclusions}

Cerebral vasospasm remains a serious complication of aneurysm SAH despite decades of research. Endovascular therapy of cerebral vasospasm has become an indispensable component in the modern armamentarium of approaches to tackling this frustrating disease process. The published data and our experience suggest that angioplasty and intraarterial vasodilation, when performed safely, promptly and thoughtfully, can significantly improve outcomes. Further refinements in balloon technology are likely to make more distal branches amenable to angioplasty. As the knowledge of the cause of cerebral vasospasm continues to advance, pharmacological approaches are also likely to advance.

\section{References}

1. Aralasmak A, Akyuz M, Ozkaynak C, Sindel T, Tuncer R: $\mathrm{CT}$ angiography and perfusion imaging in patients with subarachnoid hemorrhage: correlation of vasospasm to perfusion abnormality. Neuroradiology 51:59-93, 2009

2. Awad IA, Carter LP, Spetzler RF, Medina M, Williams F Jr: Clinical vasospasm after subarachnoid hemorrhage: response to hypervolemic hemodilution and arterial hypertension. Stroke 18:365-372, 1987

3. Badjatia N, Topcuoglu MA, Pryor JC, Rabinov JD, Ogilvy CS, Carter BS, et al: Preliminary experience with intra-arterial nicardipine as a treatment for cerebral vasospasm. AJNR Am J Neuroradiol 25:819-826, 2004

4. Beck J, Raabe A, Lanfermann H, Berkefeld J, De Rochemont Rdu M, Zanella F, et al: Effects of balloon angioplasty on perfusion- and diffusion-weighted magnetic resonance imaging results and outcome in patients with cerebral vasospasm. J Neurosurg 105:220-227, 2006

5. Biondi A, Le Jean L, Puybasset L: Clinical experience of selective intra-arterial nimodipine treatment for cerebral vasospasm following subarachnoid hemorrhage. AJNR Am J Neuroradiol 27:474, 2006

6. Biondi A, Ricciardi GK, Puybasset L, Abdennour L, Longo M, Chiras J, et al: Intra-arterial nimodipine for the treatment of symptomatic cerebral vasospasm after aneurysmal subarachnoid hemorrhage: preliminary results. AJNR Am J Neuroradiol 25:1067-1076, 2004

7. Chaudhary SR, Ko N, Dillon WP, Yu MB, Liu S, Criqui GI, et al: Prospective evaluation of multidetector-row CT angiography for the diagnosis of vasospasm following subarachnoid hemorrhage: a comparison with digital subtraction angiography. Cerebrovasc Dis 25:144-150, 2008

8. Elliott JP, Newell DW, Lam DJ, Eskridge DJ, Douville CM, Le Roux PD, et al: Comparison of balloon angioplasty and papaverine infusion for the treatment of vasospasm following aneurysmal subarachnoid hemorrhage. J Neurosurg 88:277284, 1998

9. Elsayed AA, Moran CJ, Cross DT III, Derdyn CP, Pilgram TK, Milburn JM, et al: Effect of intraarterial papaverine and/or angioplasty on the cerebral veins in patients with vasospasm after subarachnoid hemorrhage due to ruptured intracranial aneurysms. Neurosurg Focus 21(3):E16, 2006

10. Eskridge JM, McAuliffe W, Song JK, Deliganis AV, Newell DW, Lewis DH, et al: Balloon angioplasty for the treatment of vasospasm: results of first 50 cases. Neurosurgery 42:510516,1998

11. Feng L, Fitzsimmons BF, Young WL, Berman MF, Lin E, Aagaard BD, et al: Intraarterially administered verapamil as adjunct therapy for cerebral vasospasm: safety and 2-year experience. AJNR Am J Neuroradiol 23:1284-1290, 2002

12. Fergusen S, Macdonald RL: Predictors of cerebral infarction in patients with aneurysmal subarachnoid hemorrhage. Neurosurgery 60:658-667, 2007

13. Firlick AD, Kaufmann AM, Jungreis CA, Yonas H: Effect of transluminal angioplasty on cerebral blood flow in the management of symptomatic vasospasm following aneurysmal subarachnoid hemorrhage. J Neurosurg 86:830-839, 1997

14. Frontera JA, Claassen J, Schmidt JM, Wartenberg KE, Temes $\mathrm{R}$, Connolly ES Jr, et al: Prediction of symptomatic vasospasm after subarachnoid hemorrhage: the modified fisher scale. Neurosurgery 59:21-27, 2006

15. Hoh BL, Ogilvy CS: Endovascular treatment of cerebral vasospasm: transluminal balloon angioplasty, intra-arterial papaverine, and intra-arterial nicardipine. Neurosurg Clin $\mathbf{N}$ Am 16:501-516, vi, 2005

16. Ionita CC, Graffagnino C, Alexander MJ, Zaidat OO: The value of CT angiography and transcranial doppler sonography in triaging suspected cerebral vasospasm in SAH prior to endovascular therapy. Neurocrit Care 9:8-12, 2008

17. Janardhan V, Biondi A, Riina HA, Sanelli PC, Steig PE, Gobin YP: Vasospasm in aneurysmal subarachnoid hemorrhage: diagnosis, prevention, and management. Neuroimaging Clin $\mathbf{N}$ Am 16:483-496, 2006

18. Jestaedt L, Pham M, Bartsch AJ, Kunze E, Roosen K, Solymosi L, et al: The impact of balloon angioplasty on the evolution of vasospasm-related infarction after aneurysmal subarachnoid hemorrhage. Neurosurgery 62:610-617, 2008

19. Keuskamp J, Murali R, Chao KH: High-dose intraarterial verapamil in the treatment of cerebral vasospasm after aneurysmal subarachnoid hemorrhage. J Neurosurg 108:458-463, 2008

20. Kincaid MS, Souter MJ, Treggiari MM, Yanez ND, Moore A, Lam AM: Accuracy of transcranial Doppler ultrasonography and single-photon emission computed tomography in the diagnosis of angiographically demonstrated cerebral vasospasm. J Neurosurg 110:67-72, 2009

21. Kirmani JF, Alkawi A, Ahmed S, Janjua N, Khatri I, Divani AA, et al: Endovascular treatment of subarachnoid hemorrhage. Neurol Res 27 (1 Suppl):S103-S107, 2005

22. Klimo P Jr, Kestle JR, MacDonald JD, Schmidt RH: Marked reduction of cerebral vasospasm with lumbar drainage of cerebrospinal fluid after subarachnoid hemorrhage. J Neurosurg 100:215-224, 2004 


\section{Endovascular options for delayed ischemic neurological deficits}

23. Komotar RJ, Zacharia BE, Otten ML, Moco J, Lavine SD: Controversies in the endovascular management of cerebral vasospasm after intracranial aneurysm rupture and future directions for therapeutic approaches. Neurosurgery 62:897-907, 2008

24. Komotar RJ, Zacharia BE, Valhora R, Mocco J, Connolly ES Jr: Advances in vasospasm treatment and prevention. J Neurol Sci 261:134-142, 2007

25. Krejza J, Baumgartner RW: Clinical applications of transcranial color-coded duplex sonography. J Neuroimaging 14:215-225, 2004

26. Lennihan L, Mayer SA, Fink ME, Beckford A, Paik MC, Zhang $\mathrm{H}$, et al: Effect of hypervolemic therapy on cerebral blood flow after subarachnoid hemorrhage: a randomized controlled trial. Stroke 31:383-391, 2000

27. Liu JK, Couldwell WT: Intra-arterial papaverine infusions for the treatment of cerebral vasospasm induced by aneurysmal subarachnoid hemorrhage. Neurocrit Care 2:124-132, 2005

28. Lysakowski C, Walder B, Costanza MC, Tramer MR: Transcranial Doppler versus angiography in patients with vasospasm due to a ruptured cerebral aneurysm: a systematic review. Stroke 32:2292-2298, 2001

29. Macdonald RL, Pluta RM, Zhang JH: Cerebral vasospasm after subarachnoid hemorrhage: the emerging revolution. Nat Clin Pract Neurol 3:256-263, 2007

30. Megyesi JF, Findlay JM, Vollrath B, Cook DA, Chen MH: In vivo angioplasty prevents the development of vasospasm in canine carotid arteries. Pharmacological and morphological analyses. Stroke 28:1216-1224, 1997

31. Mindea SA, Yang BP, Bendok BR, Miller JW, Batjer HH: Endovascular treatment strategies for cerebral vasospasm. Neurosurg Focus 21(3):E13, 2006

32. Naidech AM, Drescher J, Tamul P, Shaibani A, Batjer HH, Alberts MJ: Acute physiological derangement is associated with early radiographic cerebral infarction after subarachnoid haemorrhage. J Neurol Neurosurg Psychiatry 77:13401344,2006

33. Romner B, Reinstrup P: Triple H therapy after aneurysmal subarachnoid hemorrhage. A review. Acta Neurochir Suppl 77:237-241, 2001

34. Rosen DS, Amidei C, Tolentino J, Reilly C, Macdonald RL: Subarachnoid clot volume correlates with age, neurological grade, and blood pressure. Neurosurgery 60:259-267, 2007

35. Rosengart AJ, Schultheiss KE, Tolentino J, Macdonald RL: Prognostic factors for outcome in patients with aneurysmal subarachnoid hemorrhage. Stroke 38:2315-2321, 2007

36. Rosenwasser RH, Armonda RA, Thomas JE, Benitez RP, Gannon PM, Harrop J: Therapeutic modalities for the management of cerebral vasospasm: timing of endovascular options. Neurosurgery 44:975-980, 1999

37. Sayama CM, Liu JK, Couldwell WT: Update on endovascular therapies for cerebral vasospasm induced by aneurysmal subarachnoid hemorrhage. Neurosurg Focus 21(3):E12, 2006
38. Schuknecht B: Endovascular treatment of cerebral vasospasm following aneurysmal subarachnoid hemorrhage. Acta Neurochir Suppl 94:47-51, 2005

39. Sedat J, Chau Y, Popolo M, Gindre S, Rami L, Orban JC: Restenosis after balloon angioplasty for cerebral vasospasm. Cardiovasc Intervent Radiol, [epub ahead of print], 2008

40. Sloan MA, Alexandrov AV, Tegeler CH, Spencer MP, Caplan LR, Feldmann E, et al: Assessment: transcranial Doppler ultrasonography: report of the Therapeutics and Technology Assessment Subcommittee of the American Academy of Neurology. Neurology 62:1468-1481, 2004

41. Smith WS, Dowd CF, Johnston SC, Ko NU, DeArmond SJ, Dillion WP, et al: Neurotoxicity of intra-arterial papaverine preserved with chlorobutanol used for the treatment of cerebral vasospasm after aneurysmal subarachnoid hemorrhage. Stroke 35:2518-2522, 2004

42. Tejada JG, Taylor RA, Ugurel MS, Hayakawa M, Lee SK, Chaloupka JC: Safety and feasibility of intra-arterial nicardipine for the treatment of subarachnoid hemorrhage-associated vasospasm: initial clinical experience with high-dose infusions. AJNR Am J Neuroradiol 28:844-848, 2007

43. Terry A, Zipfel G, Milner E, Cross DT III, Moran CJ, Diringer MN, et al: Safety and technical efficacy of over-the-wire balloons for the treatment of subarachnoid hemorrhage-induced cerebral vasospasm. Neurosurg Focus 21(3):E14, 2006

44. Weyer GW, Nolan CP, Macdonald RL: Evidence-based cerebral vasospasm management. Neurosurg Focus 21(3):E8, 2006

45. Wintermark M, Ko NU, Smith WS, Liu S, Higashida RT, Dillion WP: Vasospasm after subarachnoid hemorrhage: utility of perfusion CT and CT angiography on diagnosis and management. AJNR Am J Neuroradiol 27:26-34, 2006

46. Zubkov YN, Nikiforov BM, Shustin VA: Balloon catheter technique for dilation of constricted cerebral arteries after aneurysmal SAH. Acta Neurochir (Wien) 70:65-79, 1984

47. Zwienenberg-Lee M, Hartman J, Rudisill N, Madden LK, Smith K, Eskridge J, et al: Effect of prophylactic transluminal balloon angioplasty on cerebral vasospasm and outcome in patients with Fisher grade III subarachnoid hemorrhage: results of a phase II multicenter, randomized, clinical trial. Stroke 39:1759-1765, 2008

48. Zwienenberg-Lee M, Hartman J, Rudisill N, Muizelaar JP: Endovascular management of cerebral vasospasm. Neurosurgery 59:S139-147, 2006

Manuscript submitted November 15, 2008.

Accepted December 22, 2008.

Address correspondence to: Bernard R. Bendok, M.D., Department of Neurological Surgery, Feinberg School of Medicine, Northwestern University, 676 North St. Clair, Suite 2210, Chicago, Illinois 60611 email: bbendok@nmff.org. 